\title{
Intellectual property dispute hits US-India science accord
}

New Delhi. The Indian government appears to be dragging its feet over accepting an offer from the United States first made seven months ago to extend collaboration in science and technology between the two countries after the current phase of cooperation comes to an end in three years' time.

The main point still at issue is apparently a US demand that India revise its laws on intellectual property to cover all joint research projects that would be funded under the new agreement.

The new agreement was put forward by Elinor Constable, US assistant secretary of state for international environmental and scientific affairs, during a visit to New Delhi last November. She claimed that it would lead to an expansion in Indo-US science cooperation into the next century, and said that she looked forward to its "negotiation and approval".

Some 50 joint research projects are currently financed from the US-India fund, established in 1987 in rupees with a value equivalent to US\$110 million, and held by the American Embassy in Delhi. The fund will be exhausted by 1997 , and the latest US proposal is intended to maintain cooperation on an even larger scale than previously through joint funding of projects by the two countries.

According to Indian officials, the agreement has still not been signed because the two sides have so far failed to reach agreement on the issue of intellectual property rights (IPR). The US proposal contains a proviso stating that, unless the Indian patent law is changed, its scientists should not be allowed to embark on joint projects with Indians if the results might become commercially exploitable.

At present the Indian law of intellectual property gives protection to processes and not products. As a signatory to the general agreement on tariffs and trade (GATT), India is obliged to amend its law. Officials say the transition to the new regime will take five years. But the United States wants India to settle the IPR issue bilaterally as a precondition for renewed cooperation in science and technology.

The earlier Science and Technology Initiative, launched in 1983, was not renewed after 1991 because of differences over IPR, while the much publicized vaccine action programme introduced in 1988 was allowed to lapse for the same reason.

The delays in signing the new agreement have led many observers to conclude that the dynamics of cooperation between the two countries, which have changed frequently over the past 35 years, are once again on the wane.

K. S. Jayaraman

\section{Earthquake 'forecasters' face their critics in Japan}

Tokyo. A leading critic of Japan's earthquake prediction programme claimed last week that such prediction is not scientifically possible, that there are no reliable precursors of earthquakes, and that scientists should not mislead the Japanese public into believing that they can be predicted.

Robert Geller of Tokyo University was given, together with other critics of the programme, a rare public opportunity to express his views at a symposium in Tokyo sponsored by the Japan Science Council and the Seismological Society of Japan.

The prediction programme has consumed hundreds of millions of dollars over the past three decades without predicting any earthquakes. But even with the criticism expressed at the meeting, it seems unlikely that there will be any major changes.

Japan is the only country in the world to maintain a major research programme in earthquake prediction. The Japanese government has set up an elaborate network of seismic instruments in the populous Tokai region southwest of Tokyo, in the belief that it will be possible to predict the next major earthquake in that region and issue a warning to the public.

The programme began in the early $1960 \mathrm{~s}$, and is now entering its seventh five-year phase. Despite severe criticisms by external reviewers (see Nature, 364, 370; 1993), it received a significant 30 per cent boost of its budget this fiscal year, to $¥ 10.6$ billion (US\$109 million).

The symposium was one of a series on earthquake prediction held about every four years. It was the first to include both speakers and organizers from outside the programme. Furthermore, supporters of earthquake prediction took a back seat and confined their interventions to brief five-minute comments on presentations by their critics.

In reply to Geller, Harumi Aoki of Nagoya University, who heads the Coordination Committee for Earthquake Prediction Research in Universities, argued that Geller's definition of prediction, requiring the time, location and magnitude of an earthquake to be narrowly defined, is too restrictive.

Aoki said that other forms of prediction, such as long-term predictions and those about the likely size and position of earthquakes without specifying the precise time, are also useful to the public.

Hiroshi Wakita of Tokyo University, another leader of the prediction programme, vigorously defended his research on radon. Geller produced records of radon measurements by Wakita, which seemed to indicate no reliable pattern between the occurrence of radon anomalies and of earthquakes.

But Wakita said that each anomaly must be looked at individually, taking into account background noise caused by weather and non-seismic crustal deformation, in order to interpret his data correctly. He also pointed out that he had published a paper in Science that had been seen by three referees.

While other critics were milder in their calls for reform, Geller said that the pro-

\section{IMAGE UNAVAILABLE FOR COPYRIGHT REASONS}

\section{st year's earthquake came without warning.}

gramme should be replaced with a basic research programme in seismology that is not given the impossible goal of predicting earthquakes.

But even many of his supporters feel this view is too extreme, and that a wide-ranging reform of the existing programme would be sufficient. They argue that cancellation could result in funds being diverted to Japan's disaster prevention programme, which industry is keen to see expanded, and support would thus be lost for research.

In practice, cancellation seems unlikely for at least five years. Reformers had drawn hope from a comment from Yukiko Hirakawa, the Ministry of Education, Science and Culture's planning director of global environment research. She recently took administrative responsibility for the prediction programme, and was quoted in the 17 June issue of Science as saying "I'm embarrassed to admit this, but until I took over this position I thought earthquake prediction was much more advanced".

But after what she describes as a "deep study of the programme", Hirakawa says that she has now changed her opinion. "Although there are many problems to be solved to achieve a practical method of earthquake prediction, society's expectations are so high that the programme is most unlikely to end", she says.

Hirakawa claims that Aoki's rebuttal of Geller's criticisms was "very convincing", adding that the government has "absolutely no intention" of revising the programme from the start of the seventh five-year phase.

David Swinbanks 